УДК 624.131

\title{
АНАЛИЗ ДЕФОРМАЦИЙ ПРОЖЕКТОРНОЙ МАЧТЫ ПРИ ПОМОЩИ НАЗЕМНОГО ЛАЗЕРНОГО СКАНИРОВАНИЯ И МЕТОДА КОНЕЧНЫХ ЭЛЕМЕНТОВ
}

\author{
Епифанова Екатерина Александровна', \\ epifanovaea@tpu.ru \\ Строкова Людмила Александровна', \\ sla@tpu.ru \\ 1 Национальный исследовательский Томский политехнический университет, \\ Россия, 634050, г. Томск, пр. Ленина, 30.
}

Актуальность темы обусловлена необходимостью усовершенствования подходов к оценке и прогнозу деформаций высокомачтовых опор. Решение этой задачи сопряжено с многими неопределенностями, такими как недостаточность лабораторных исследований свойств материалов и полевых статических и динамических испытаний подобного рода сооружений, малочисленность аналитических исследований и мониторинговых данных. Представлены первоначальные результаты полевых исследований деформаций прожекторной мачты и численного анализа ее напряженно-деформированного состояния.

Целью исследования является оценка напряженно-деформированного состояния грунтового основания сооружения и сравнение результатов численного моделирования с данными по деформациям объекта, полученными в ходе лазерного сканирования. объект - напряженно-деформированное состояние грунтового основания прожекторной мачты на Ванкорском нефтяном месторождении

Методика. Исходными данными для моделирования поведения сооружения послужили данные рекогносцировочного обследования участка. Для характеристики напряженно-деформированного состояния сооружения использовался программный комплекс на базе МКЭ. Для оценки деформаций и построения точной трехмерной модели объекта использовалась технология лазерного сканирования. Сканирование объекта проводилось лазерным 3D сканером Leica Scanstation C10, планово-высотное обоснование и привязка пунктов обоснования к местной системе координат с использованием электронного тахеометра LEICA TS15 и GNSS приемника LEICA GS10, обработка массива точек проводилась в программном комплексе Leica Cyclone 8.0, трехмерное моделирование объекта было осуществлено в программном комплексе SolidWorks.

Результаты. Оценено напряженно-деформированное состояние грунтового основания. Создана цифровая расчетная модель. Выполнено сравнение результатов моделирования с пространственно-координатным положением конструкций, установленным при лазерном сканировании. Оценен вклад грунтовых условий в деформации сооружения.

\section{Ключевые слова:}

Лазерное сканирование, моделирование, деформации, механические свойства, напряженно-деформированное состояние, метод конечных элементов.

\section{Введение}

Наблюдение за сложными техническими сооружениями при их эксплуатации является наиболее эффективным способом предотвращения аварийных ситуаций. Анализ отечественных и зарубежных [1-29] исследований показал, что в последние годы ведутся работы по совершенствованию методов геотехнического мониторинга объектов. Объективная оценка технического состояния сооружения может быть получена при комплексировании методов по оценке геометрии объекта и метода конечных элементов (МКЭ) для выяснения причин деформаций, обусловленных инженерногеологическими условиями участка.

Цель работы: оценить напряженно-деформированное состояние грунтового основания сооружения и сравнить результаты численного моделирования с данными по деформациям объекта, полученными в ходе лазерного сканирования.

В качестве объекта для проведения технического контроля была выбрана прожекторная мачта на Ванкорском нефтегазовом месторождении, которое расположено в Туруханском районе Красноярского края, на водоразделе р. Большая Хета и р. Лодочная (рис. 1).

\section{Характеристика инженерно-геологических условий}

Территория Ванкорского месторождения в инженерно-геологическом отношении изучена довольно подробно в последние тридцать лет.

В геолорфологическол отношении территория принадлежит Нижнеенисейской низменности, представлена в основном моренной равниной ермаковского оледенения с абсолютными отметками поверхности земли 24...64 м. Характер рельефа здесь является типичным для краевых ледниковых областей. Его образование происходило во время отступания ледника (в его краевой зоне) в условиях длительной задержки и постепенного таяния. Также здесь повсеместно развит камовый рельеф и широкое распространение имеет Ангутихинская озерно-ледниковая равнина.

Гидрографическая сеть района изысканий сформирована притоками р. Большая Хета (левый приток р. Енисей). Реки равнинные, с корытообразным поперечным профилем, часто меандрируют. Основными источниками питания рек служат дождевые и талые воды. Территория характеризуется значительной заозеренностью $(10 \%)$. Преобладают (около 90 \%) мелководные и небольшие по размерам озера, площадь водного зеркала кото- 


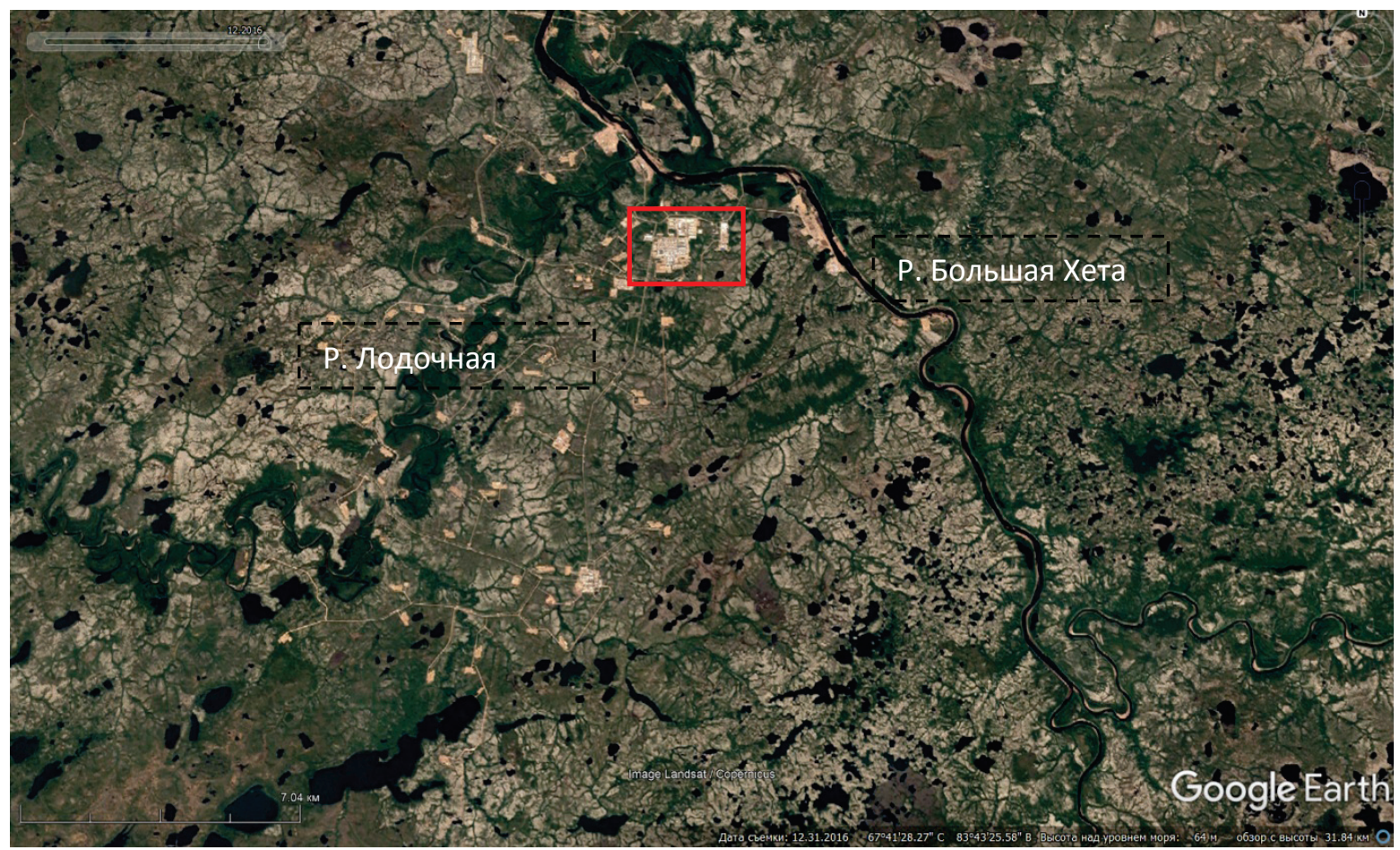

Pис. 1. Снимок междуречья Большая Хета и р. Лодочная, район работ обозначен красныл контуром, масштаб 1:100000

Fig. 1. Satellite image of the Bolshaya Kheta - Lodochnaya interfluve, the study area is in red outline, scale 1:100000

рых не превышает $1 \mathrm{kм}^{2}$. Это в основном термокарстовые озера с глубиной $2 . . .3$ м, в зимний период они полностью промерзают. Некоторые озера соединены между собой ручьями, образующими единую озерно-речную систему. Протоки, соединяющие озера, также полностью промерзают зимой. Несквозные подозерные талики формируются чаще всего под озерами, глубина которых превышает 2 м. В зависимости от размеров, возраста и генезиса озер мощность подозерных таликов может достигать $50 . .70$ м. Под водораздельными озерами глубиной до $10 \mathrm{м} \mathrm{мощность} \mathrm{таликов} \mathrm{составляет}$ $15 . .20$ м. В летний период обильных дождей и сезонного оттаивания многолетнемерзлых пород движение транспортных средств становится весьма затруднительным, а в некоторых случаях невозможным.

Клилат района изысканий в значительной степени определяется его географическим положением в высоких широтах, близостью Арктического бассейна, влиянием арктических и атлантических воздушных масс, характером рельефа. Зимой, продолжительность которой достигает восемь и более месяцев (с октября по апрель, нередко и май), преобладают западные и юго-западные воздушные течения. В летний период над территорией преобладают северные вторжения арктических масс холодного и сухого воздуха континентального типа, распространение которых приводит к установлению относительно малооблачной погоды антициклонального типа и к резкому понижению температуры воздуха. В общем для района характерна частая смена направления воздушных течений, чем объясняется неустойчивость погоды в течение всего года. Среднегодовая скорость ветра в исследуемом районе составляет $3 . .5 \mathrm{~m} / \mathrm{c}$, а максимальная скорость ветра может достигать $30 \mathrm{~m} / \mathrm{c}$.

Солнечная радиация является главным источником тепловой энергии для всех природных процессов. Ближайшая к району исследования метеорологическая станция, где проводятся наблюдения за характеристиками солнечной радиации, - Игарка. Температура воздуха исследуемой территории имеет положительные значения с июня по сентябрь. Среднегодовая температура воздуха варьирует от $-6,7$ до $-10,2{ }^{\circ} \mathrm{C}$. Годовая амплитуда колебаний среднемесячных температур воздуха составляет $43 . .44{ }^{\circ} \mathrm{C}$. Продолжительность периода с отрицательными температурами составляет 225...255 дней. Самый холодный месяц в году - январь. Средняя температура воздуха в январе $-27 . .-29^{\circ} \mathrm{C}$, наиболее теплого месяца - июля $14 \ldots 17^{\circ} \mathrm{C}$.

Среднегодовое количество осадков в изучаемом районе составляет $480 . .540$ мм, в холодный период года выпадает $260 \ldots 330 \mathrm{~mm}$, в теплый 200...260 мм. Максимальное количество осадков за месяц наблюдается в августе и сентябре, что способствует увеличению коррозии металлических конструкций и дополнительному протаиванию сезонно-талого слоя, минимальное количество осадков - в феврале-марте. Среднегодовая относительная влажность воздуха в районе исследований составляет $75 . .78 \%$, с максимумами в октябре и минимумами в июне-июле. 
Снежный покров является важным промежуточным звеном в теплообмене грунтов с атмосферой, поэтому его влияние на температурный режим грунтов является наиболее значительным. Теплоизолирующий эффект снежного покрова зависит от режима его формирования, высоты, плотности и процессов, происходящих внутри снежной толщи. По многолетним наблюдениям на метеостанциях Игарка и Советская Речка, устойчивый снежный покров образуется в начале октября и сохраняется в течение 8...8,5 месяцев. Максимальная мощность составляет $60 \ldots 70 \mathrm{~cm}$, причем наблюдается закономерное возрастание с запада на восток, где мощность снежного покрова на значительной территории превышает $80 \mathrm{~cm}$.

Геологическое строение. В геологическом отношении объект расположен на границе Сибирской и Западно-Сибирской платформ, под чехлом мезокайнозойских отложений. Осадочные отложения четвертичной системы, мощностью до $50 \ldots 115 \mathrm{M}$, развиты повсеместно. В разрезе четвертичные отложения представлены, как правило, грунтами покровного (делювиального), озерно-аллювиального, морского, ледникого генезиса.

В геологическом строении промышленной площадки представлены следующие комплексы: техногенных грунтов; верхнеплейстоценовых и голоценовых аллювиальных и озерно-аллювиальных отложений $\left(\mathrm{a}, \mathrm{la} \mathrm{Q}_{\text {III-IV }}\right)$ и верхнеплейстоценовых моренных отложений $\left(\mathrm{g}, \mathrm{f}, \lg \mathrm{Q}_{\mathrm{III}}\right)$ ермаковской свиты.

Комплекс техногенных грунтов распространен на глубину 5,5 м. Техногенный грунт отсыпан мелкозернистым пылеватым серым песком.

Верхнеплейстоценовые и голоценовые аллювиальные и озерно-аллювиальные отложения (a, laQ приурочены, как правило, к озерно-болотным котловинам, долинам рек, межозерным пространствам. В районе исследований имеют мощность до 20,9 м и залегают на отложениях ермаковской свиты. Представлены суглинками и супесями серыми с примесями торфа.

Отложения ермаковской свиты развиты практически повсеместно, являясь рельефообразующими. Состав пород преимущественно супесчано-суглинистый, с включениями гравия, гальки и валунов, с прослоями и отдельными линзами песков от пылеватых до мелких. Отложения верхней части ермаковской свиты слагают наиболее высокие водораздельные поверхности. Мощность свиты до $60 \mathrm{M}$.

Геокриологические условия. Рассматриваемая территория принадлежит к области сплошного распространения многолетнемерзлых пород (ММП), мощность которых по данным бурения промысловых и разведочных скважин составляет $450 \ldots 480$ м. Несквозные талики прослеживаются только под наиболее крупными озерами и реками. В прирусловых частях крупных рек долинного комплекса характерны минимальные мощности ММП - до 50 м. В поймах более мелких водотоков мощность их увеличивается до $100 \ldots 150$ м.
Среднегодовая температура мерзлых пород, на подошве слоя годовых колебаний, от $-1,5$ до $-2,5{ }^{\circ} \mathrm{C}$. Во всех отрицательных формах рельефа, в которых зимой накапливается мощный снежный покров, наблюдаются таликовые участки, в основном инфильтрационного типа. Мощность их, как правило, не превышает $2 . . .6$ м.

Гидрогеологические условия. В гидрогеологическом отношении Ванкорское месторождение приурочено к краевой части северо-восточной зоны Западно-Сибирского артезианского бассейна, в разрезе которого выделяются несколько водоносных комплексов. Гидрогеологические комплексы объединены в два гидрогеологических этажа. Глинистые породы дорожковской свиты рассматриваются как региональный туронский флюидоупор, разделяющий проницаемые горизонты верхнего и нижнего гидрогеологических этажей, мощность которой в пределах месторождения составляет 150 м.

В нижнем гидрогеологическом этаже выделяют три водоносных комплекса: юрский, неокомский и апт-альб-сеноманский. Для Ванкорского месторождения характерно сложное изменение минерализации с глубиной. Пласты апт-альб-сеноманского комплекса содержат воды преимущественно хлоридно-кальциевого типа, по В.А. Сулину, а верхнего мела и неокомского комплекса - гидрокарбонатно-натриевого типа.

Верхний гидрогеологический этаж образован двумя гидрогеологическими комплексами. Его гидрогеологические условия в большей степени предопределяются наличием в районе мощной толщи многолетнемерзлых пород (ММП), исключивших из водообмена значительную часть подземных вод. Первый гидрогеологический комплекс составляют отложения дорожковской, насоновской, салпадинской и танамской свит позднемелового возраста. Второй гидрогеологический комплекс представлен терригенными песчано-алевритистыми и глинистыми отложениями четвертичного возраста мощностью до 93 м.

На рассматриваемой территории выделяются надмерзлотные воды, воды сквозных таликов, межмерзлотные (внутримерзлотные) воды и подмерзлотные воды.

Надмерзлотные воды. Этот класс подземных вод включает в себя воды сезонно-талого слоя (CTC) и воды надмерзлотных (несквозных) таликов. Нижним водоупором этих вод является толща многолетнемерзлых пород. Мощность СТС изменяется от 1 до 6 м. Химический состав вод СТС близок к составу поверхностных вод и атмосферных остатков: это воды ультрапресные, гидрокарбонатные или сульфатно-гидрокарбонатные, магниевые или кальциевые. Их минерализация изменяется в пределах от 0,05 до 0,4 г/л. Воды надмерзлотных (несквозных) таликов гораздо менее распространены. Эти воды, как правило, относятся к гидрокарбонатному кальциевому, магниевому или натриевому типам. Воды пресные, их минерализация составляет $0,1 . .1,0$ г/л. Водоносные комплек- 
сы надмерзлотных таликов не имеют существенного значения для водоснабжения, но иногда используются для временного водоснабжения небольших объектов.

Воды сквозных таликов приурочены к долинам крупных водотоков и котловинам наиболее крупных озер, а также к зонам отдельных тектонических нарушений. Как правило, эти воды гидрокарбонатные, кальциевые или магниевые, пресные с минерализацией до 1 г/л. Данный водоносный комплекс является основным потенциальным источником вод для хозяйственно-питьевого водоснабжения в силу их высокой водообильности и качества подземных вод.

Подмерзлотные воды, залегающие ниже подошвы многолетнемерзлых пород, характеризуется повсеместным распространением и включает в себя ряд водоносных комплексов, характеризующихся единством условий питания, фильтрации и разгрузки, но приуроченных к различным водовмещающим породам с соответствующими значениями коэффициента фильтрации и имеющих различный химический состав и минерализацию. По классификации В.А. Сулина, воды в основном относятся к гидрокарбонатно-натриевому типу, с минерализацией до 3,9 г/л.

Геологические и инженерно-геологические проиессы. По карте ОСР-97-В (5\%-я вероятность возможного превышения в течение 50 лет указанных на карте значений сейсмической интенсивности) сейсмичность района менее 5 баллов.

К самым распространенным криогенным процессам, развитым на территории, относится криогенное пучение, термокарст и солифлюкция.

Процесс криогенного пучения характеризуется поднятием поверхности почвы и породы, вызванным увеличением их объема при промерзании. В результате криогенного пучения возникают бугры пучения, размером от метра и более. Необходимо отметить, что к криогенному пучению относятся процессы сезонного (для СТС) и многолетнего (для ММП) пучения. Наиболее значимо многолетнее пучение, которое приводит к поднятию отдельных участков (площадное пучение) на $0,4 \ldots 0,8$ м. В инженерно-геологическом отношении эта форма морозного пучения наиболее значима. Также для СТС широко развито образование пятен-медальонов вследствие выпучивания мелкообломочного материала при сезонном промерзании грунта.

Процессы термокарста развиваются по льдистым отложениям и четко проявляются в формировании отрицательных форм рельефа.

На изучаемой территории развитие солифлюкционных процессов характерно для СТС. Отмечено вязкое/вязкопластичное течение оттаявшего грунта СТС по поверхности ММП на склонах. Благоприятствуют развитию солифлюкции здесь геоморфологические и литологические условия. Для предотвращения солифлюкции необходим, прежде всего, организованный отвод вод в сезон таяния с близлежащих склонов.
Широко распространенное в породах СТС морозобойное растрескивание определяет формирование полигонально-блочного рельефа.

Мощность сезонноталого слоя - величина непостоянная, зависящая от климатического фактора. Изменчивость величины сезонного протаивания в разные годы, в связи с климатическими колебаниями, достигает $10 . .30$ \% . В суглинках величины сезонного оттаивания составляют $0,7 \ldots 1,1 \mathrm{M}$, в супесях и песках - до 1,5...2,0 м.

При освоении территории рекомендуются мероприятия, направленные на предотвращение активизации процессов термокарста и морозного пучения (замена грунта на непучинистый, удаление влаги из грунта, удаление грунта).

Техногенное воздействие. Следует отметить, что на промплощадке к наиболее негативным свойствам грунтов следует отнести предрасположенность связных грунтов к проявлению тиксотропии. Данное свойство провоцируется динамическим воздействием на грунты (проезд транспорта, особенно гусеничного, работа вибрационных механизмов и т. п.), когда нарушаются критические расстояния между частицами, следствием чего является переход связанной воды в свободную форму, грунт разжижается, теряя свою структурную прочность. Результатом динамических воздействий на приповерхностные грунты является повышение уровня оттаивания СТС осваиваемой территории. Техногенное воздействие на рассматриваемый участок постепенно возрастает, что обусловлено расширением обустройства Ванкорского месторождения.

Заключая знакомство с инженерно-геологическими условиями участка, можно предположить, что деформации мачты могут быть обусловлены специфическими характеристиками грунтового основания: высокой сжимаемостью грунтов сезонно-талого слоя, ползучестью многолетнемерзлых пород в длительной перспективе и изменениями механических свойств грунтов при вариациях их температурного режима. Моделирование напряженно-деформированного состояния грунтового основания позволит оценить вклад грунтовых условий в деформациях мачты. Для верификации расчетов прежде необходимо оценить фактические перемещения конструкции в пространстве. Их определение представлено ниже.

\section{Наземное лазерное сканирование объекта}

Одной из самых прогрессивных универсальных технологий по оценке геометрии объектов является наземное лазерное сканирование (НЛС). Преимущества использования наземного лазерного сканирования по сравнению с традиционными методами наблюдения определяются высокой точностью геометрических параметров - до 4 мм; скоростью съемки до 60000 точек в секунду; низкой себестоимостью работ - до $40 \%$ ниже, чем при традиционной геодезической съемке [11-21]. Полевые работы выполнялись лазерным сканером Leica ScanStation C10. 
Процесс контроля можно разделить на два этапа: 1) полевые работы: получение первоначальных геометрических параметров мачты - облако точек (рис. 2); 2) камеральные работы: обработка полученных материалов полевых работ.

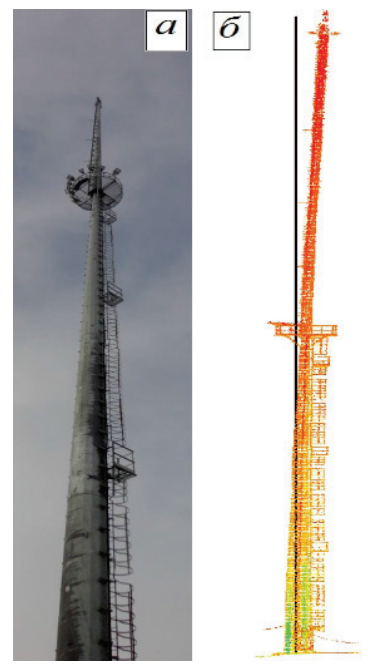

Pис. 2. Прожекторная мачта: а) фотография; б) результат ла зерного сканирования - облако точек с проектной осью

Fig. 2. High-mast lighting tower: a) photography; б) laser scanning result - point cloud with project axis
Определение оси мачты проводилось следующим образом. Через каждые два метра и на стыках секций производились поперечные сечения облака точек мачты. Затем в получившийся разрез вписывался многоугольник, центр которого совпадает с осью мачты. Полученные центры затем соединялись линией, образуя ось мачты. Важно уточнить, что на стыках секций делалось два разреза - нижней и верхней секции, в результате чего были получены корректные оси для каждой секции отдельно.

Полученный набор сечений и ось показывают отклонение осей секций друг от друга не только в местах соединений, но и искажение геометрии мачты по всей длине секции. Дальнейшая обработка результатов и измерение геометрических характеристик мачты производилась с помощью $\mathrm{Au}-$ toCAD.

Обследование общего отклонения мачты. На основе измерений составлены две диаграммы отклонения существующей оси от вертикальной оси мачты в направлениях запад-восток и юг-север (рис. 3). Из диаграмм следует, что отклонение вершины мачты на восток $~ 5,7 \mathrm{~cm}$, на юг $~ 7,2$ см. Отклонение вершины молниеотвода на восток $\sim 8,3 \mathrm{~cm}$, на юг $\sim 4,7$ см. Из диаграмм также следует, что наклон мачты происходит не только в местах соединения секций, но и по всей длине одной
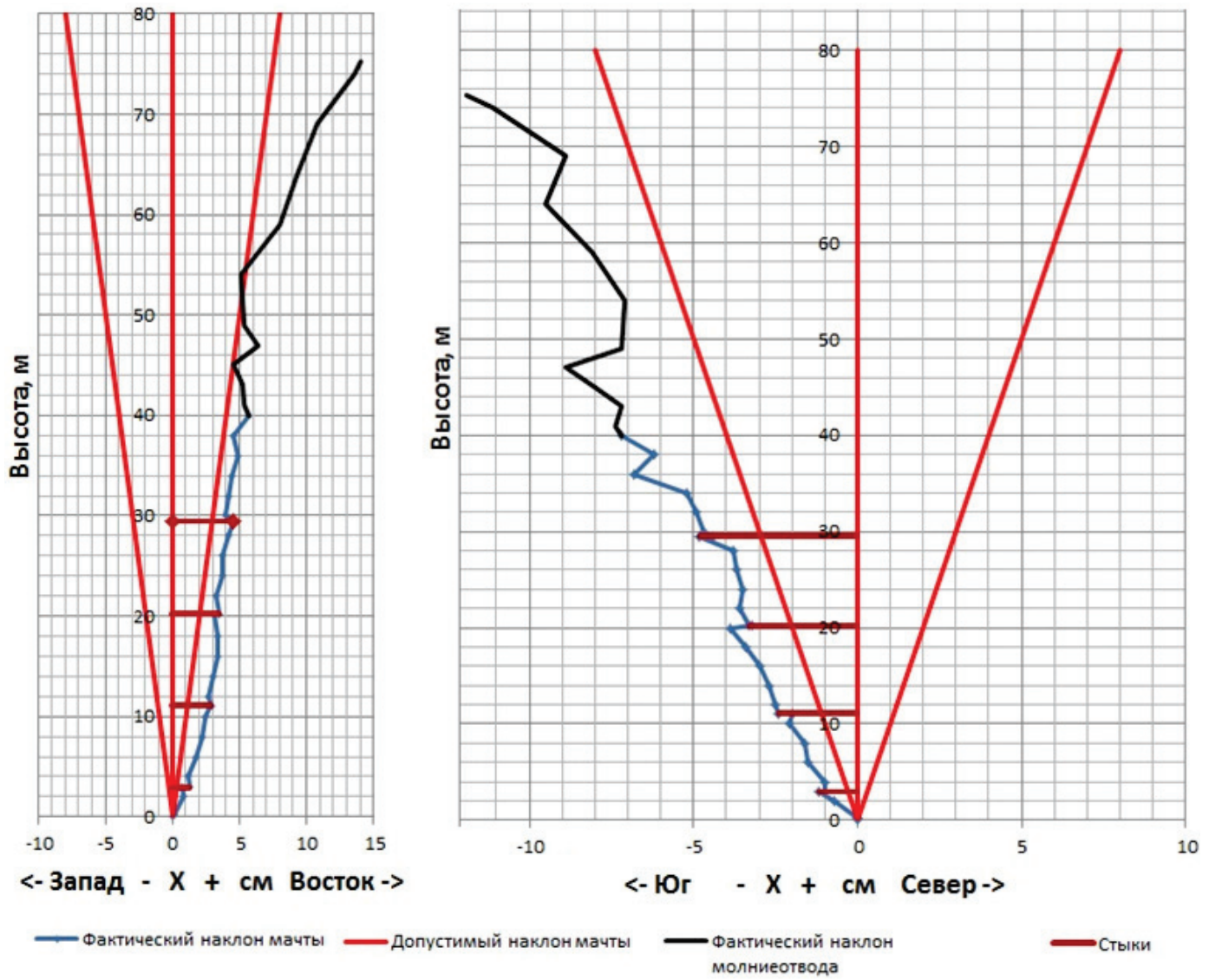

Pис. 3. Отклонение мачты и молниеотвода в направлениях запад-восток и юг-север

Fig. 3. Deflection of the mast and lightning rod in the directions West-East and South-North 

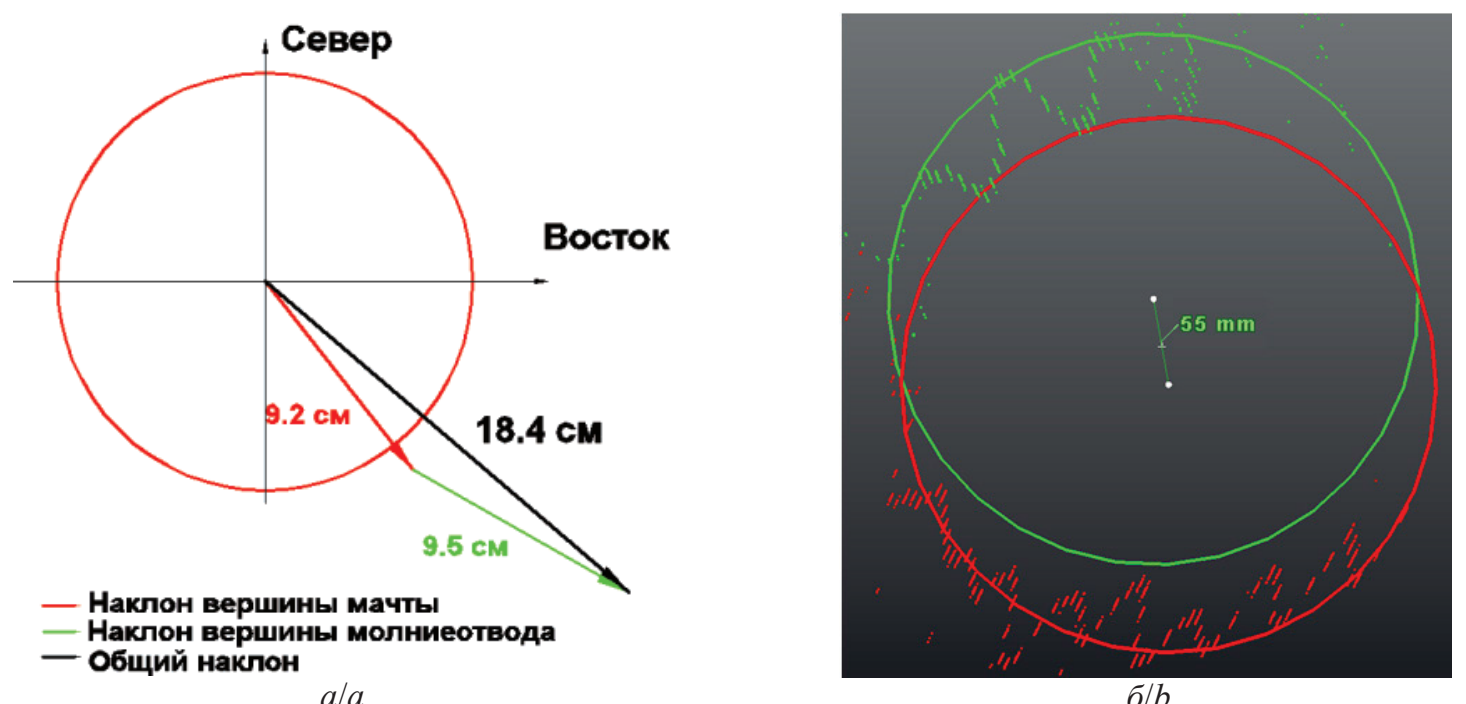

Pис. 4. Направление отклонения молниеотвода на нулевой отметке (а) и высоте 70 м (б)

Fig. 4. Direction of lightning rod deviation at a height of (a) 0 and (б) 70 meters

секции. Итоговое отклонение от вертикальной оси (рис. 4, вид сверху) составило: для вершины мачты 9,2 см, для вершины молниеотвода 9,5 см. Общее отклонение от вертикальной оси мачты с молниеотводом составило 18,4 см в направлении юго-восток (рис. $4, a$ ). На рис. 4 , б представлена диаграмма колебания оси молниеотвода, которые достигают 6 см на высоте 70 м.

Обследование зазоров зон стяжек производилось следующим образом. В местах соединения секций проводился поперечный разрез мачты в горизонтальной плоскости. Подсчитаны зазоры между внешней поверхностью нижней секции и внутренней поверхностью верхней секции в четыpex направлениях. Полученные данные представлены в табл. 1. Значение максимального зазора составило $22 \mathrm{~mm} \mathrm{в} \mathrm{месте} \mathrm{соединения} \mathrm{секций}$ CBB40-1 и CBB40-2 с западной стороны мачты.

По результатам обследования зон стяжек мачты M2 выявлено несоблюдение допуска ( \pm 100 мм) размеров зон стяжек секций СВВ40-4 и СВВ40-3: длина их стяжек равна 1939 и 1372 мм вместо положенных $1800 \pm 100$ и $1500 \pm 100$ мм соответственно.

таблица 1. Зазоры в местах соединений секций

Table 1. Gaps in the joints of sections

\begin{tabular}{|c|c|c|c|c|}
\hline \multirow[b]{2}{*}{$\begin{array}{l}\text { Соединения секций } \\
\text { Joints of the sections }\end{array}$} & \multicolumn{4}{|c|}{ Зазор, мм/Gap, mm } \\
\hline & $\begin{array}{c}\text { Запад } \\
\text { East }\end{array}$ & $\begin{array}{c}\text { Восток } \\
\text { West }\end{array}$ & $\begin{array}{l}\text { Север } \\
\text { North }\end{array}$ & $\begin{array}{c}\text { Юг } \\
\text { South }\end{array}$ \\
\hline CBB40-1+CBB40-2 & 22 & 0 & 8 & 2 \\
\hline CBB40-2+CBB40-3 & 2 & 4 & 9 & 0 \\
\hline CBB40-3+CBB40-4 & 2 & 0 & 1 & 1 \\
\hline CBB40-4+CBB40-5 & 5 & 1 & 2 & 7 \\
\hline
\end{tabular}

Обследование отклонений осей секиий друг от друга (табл. 2) производилось в следующей последовательности. Вначале соединялись центры верхней и нижней граней одной секции, образуя ось секции. Затем измерялся угол между этими осями секций $(\alpha) . \beta$ - это угол между осями секций, проведенными через центры сечений. В случаях, когда оси секций не совпадали, было подсчитана высота, на которой эти оси должны пересечься (H). Если пересечение происходило выше стыка, значению высоты присваивался знак плюс, если ниже минус. Также подсчитана высота, на которой должны пересекаться оси, проведенные через центры сечений секции (Н').

По результатам обследования искривления стенок в пределах каждой секции в направлениях север, юг, запад и восток выявлено максимальное отклонение стенок от идеальной формы: 18 мм на секции СBВ40-1. Максимальный угол отклонения, который составил $37^{\prime} 29^{\prime \prime}$, в месте соединения секций СBВ40-2 и СBB40-1.

Итак, при наземном лазерном сканировании получено облако точек, на основе которого созданы фактические контуры конструкции мачты М2. Установлено, что колебание мачты из-за ветра негативно влияет на результат съемки. Так, выше 50 м обработка данных становится затруднительной из-за большого разброса облака точек и невозможности нахождения точной оси мачты.

\section{Численное моделирование напряженно-}

деформированного состояния основания мачты

В работах [30-37] по численному моделированию поведения грунтовых массивов во взаимодействии с различными инженерными сооружениями (виадук, магистральный трубопровод, метрополитен, историческое здание театра, подпорная стенка, при упрочнении грунтового массива цементнопесчаной инъекцией) показаны преимущества использования МКЭ в актуализации расчетных моделей при реконструкции сооружений и предотвращении аварийных ситуаций.

Объектом настоящего исследования являлось напряженно-деформируемое состояние (НДС) 
Таблица 2. Отклонения секций друг от друга на месте соединения

Table 2. Deviation of sections from each other at the junction

\begin{tabular}{|c|c|c|c|c|c|c|c|c|}
\hline \multirow{2}{*}{$\begin{array}{c}\text { Соединения } \\
\text { секций } \\
\text { Joints } \\
\text { of the sections }\end{array}$} & $180-\alpha$ & $\begin{array}{l}\text { Н стяжки, мм } \\
\text { H screed, mm }\end{array}$ & $180-\alpha$ & \begin{tabular}{|c|} 
Н стяжки, мм \\
H screed, mm
\end{tabular} & $180-\beta$ & $\begin{array}{c}\text { H' стяжки, мм } \\
\text { H screed, mm }\end{array}$ & $180-\beta$ & \begin{tabular}{|l|} 
Н' стяжки, мм \\
H screed, mm
\end{tabular} \\
\hline & \multicolumn{2}{|c|}{$\begin{array}{l}\text { Запад-Восток } \\
\text { East-West }\end{array}$} & \multicolumn{2}{|c|}{$\begin{array}{l}\text { Юг-Север } \\
\text { South-North }\end{array}$} & \multicolumn{2}{|c|}{$\begin{array}{l}\text { Запад-Восток } \\
\text { East-West }\end{array}$} & \multicolumn{2}{|c|}{$\begin{array}{l}\text { Юг-Север } \\
\text { South-North }\end{array}$} \\
\hline CBB40-5+CBB40-4 & 2'21" & -680 & $10^{\prime} 29^{\prime \prime}$ & 8935 & 5'37" & 3702 & $23^{\prime} 31^{\prime \prime}$ & -331 \\
\hline CBB40-4+CBB40-3 & $15^{\prime} 35^{\prime \prime}$ & 11883 & 1'4" & 735 & $18^{\prime} 22^{\prime \prime}$ & 209 & 7'19" & -1736 \\
\hline CBB40-3+CBB40-2 & $2 ' 15^{\prime \prime}$ & -2561 & 2'49" & -4729 & 2'13" & 5118 & $2^{\prime} 49^{\prime \prime}$ & 6903 \\
\hline CBB40-2+CBB40-1 & $37^{\prime} 29 "$ & 1985 & 2'53" & - & $37^{\prime} 29^{\prime \prime}$ & 23 & 2'53" & 4554 \\
\hline
\end{tabular}

грунтового основания мачты (рис. 5). Работа проводилась с использованием программного комплекса конечноэлементного анализа Plaxis. При моделировании были приняты следующие механические характеристики материала мачты (сталь С 345 , $12 \Gamma 2 \mathrm{C}, 09 \Gamma 2 \mathrm{C})$ : модуль упругости $E=2 \cdot 10^{11}$ Па, коэффициент Пуассона $v=0,29$, плотность $\rho=7850 \mathrm{\kappa г} / \mathrm{M}^{3}$, предел текучести $\sigma_{\tau}=345$ МПа. Вес мачты с молниеотводом и метизами 11534 кг.

Фундамент мачты состоит из четырех винтовых металлических свай СВ-325-6.0, расположенных по углам квадрата со стороной 2 м (рис. 5). На сваи установлен и приварен четырёхсвайный ростверк (523 кг), состоящий из опорной плиты (толщиной 10 мм) и двух швеллерных балок № 20, установленных на опорные столики свай. Сваи и ростверк изготовлены из стали класса С 345 и покрыты от коррозии битумнонаиритовой композицией. Соединение всех элементов фундамента между собой произведено посредством ручной сварки постоянным током. При моделировании приняты следующие механические характеристики ростверка и свай: модуль упругости $E=2 \cdot 10^{11}$ Па, коэффициент Пуассона $v=0,33$.

Таблица 3. Свойства грунтов

Table 3. Soil data sets parameters

\begin{tabular}{|c|c|c|c|c|c|c|}
\hline \multicolumn{2}{|c|}{$\begin{array}{c}\text { Грунты (Soils) } \\
\text { Параметры } \\
\text { Parameters }\end{array}$} & \multirow[t]{2}{*}{ 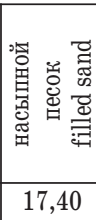 } & \multirow{2}{*}{ 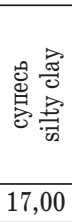 } & \multirow[t]{2}{*}{ 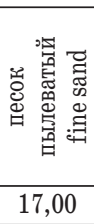 } & \multirow[t]{2}{*}{ 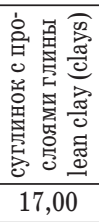 } & \multirow[t]{2}{*}{ 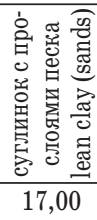 } \\
\hline$\gamma_{\text {unsat }}$ & {$\left[\mathrm{kN} / \mathrm{m}^{2}\right]$} & & & & & \\
\hline$\gamma_{\text {sat }}$ & {$\left[\mathrm{kN} / \mathrm{m}^{2}\right]$} & 18,00 & 20,00 & 18,00 & 18,00 & 18,00 \\
\hline $\mathrm{E}_{\mathrm{ref}}$ & {$\left[\mathrm{kN} / \mathrm{m}^{2}\right]$} & 12000 & 10000 & 13000 & 10000 & 50000 \\
\hline$v$ & {$[-]$} & 0,3 & 0,3 & 0,350 & 0,350 & 0,3 \\
\hline $\mathrm{G}_{\mathrm{ref}}$ & {$\left[\mathrm{kN} / \mathrm{m}^{2}\right]$} & 5000 & 5000 & 3703 & 3704 & 19231 \\
\hline $\mathrm{E}_{\text {oed }}$ & {$\left[\mathrm{kN} / \mathrm{m}^{2}\right]$} & 17500 & 17500 & 16049 & 16049 & 67307 \\
\hline $\mathrm{c}_{\text {ref }}$ & {$\left[\mathrm{kN} / \mathrm{m}^{2}\right]$} & 1 & 5 & 1 & 20 & 20 \\
\hline$\varphi$ & {$\left[{ }^{\circ}\right]$} & 31 & 25 & 27 & 25 & 25 \\
\hline
\end{tabular}

Геологический разрез изучен на глубину 18 м и представлен пятью инженерно-геологическими элементами. Первым от поверхности залегает насыпной песок, мощностью 5,5 м, ниже которого залегает супесь бурая, мерзлая, льдистая (льдистость за счет видимых ледяных включений $i_{i}$ составляет $20 . .22 \%$ ), слойсто-сетчатой криотекстуры, с ожелезнением, мощностью до 2 м. Под супе- сью залегает песок темно-серый, пылеватый, мерзлый, слабольдистый, массивной криотекстуры, мощностью 1 м. Ниже песка залегает суглинок синевато-серый, мерзлый, льдистый $\left(i_{i}-25 . . .30 \%\right)$, слоистосетчатый криотекстуры с прослойками глины, мощностью 2,5 м. Ниже залегает суглинок синевато-серый, мерзлый, слабольдистый $\left(i_{i}-\right.$ $4 . .7 \%$ ) с тонкими прослоями песка и включениями гальки до $5 \%$. Граница сезонно-талого слоя находится ни глубине 6 м от поверхности земли. Физико-механические свойства грунтов указаны в табл. 3.

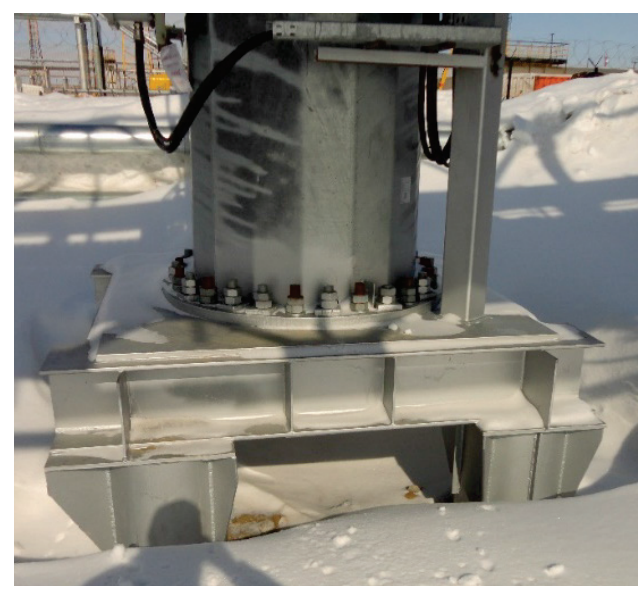

Pис. 5. Основание мачты

Fig. 5. Mast foundation

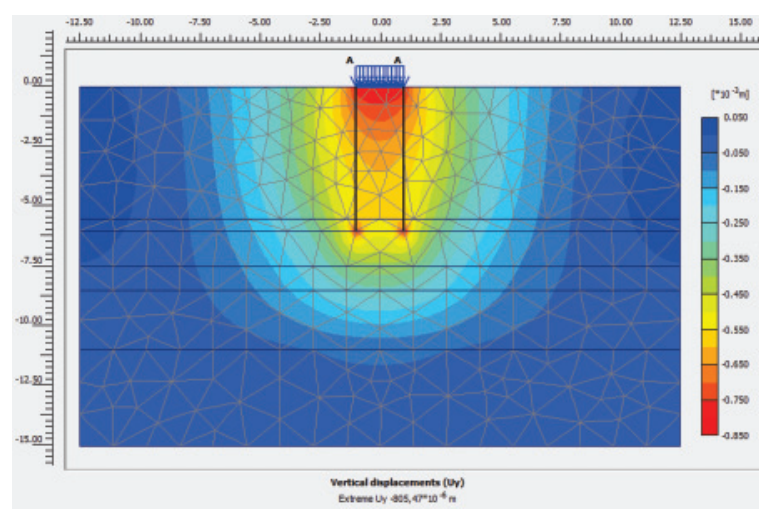

Pис.6. Конечно-элементная сетка и изополя вертикальных перемешений

Fig. 6. Finite element mesh and vertical displacements 
Дискретизация расчетной области выполнена треугольными элементами. В расчетах использовалась упруго-пластическая модель Plaxis MohrCoulomb. Ростверк моделировался жесткой плитой, опертой на межузловые анкеры. Вес мачты передавался на фундамент при помощи опции Distributed static load A-A (2885 кг/м²). Расчеты вертикальных перемещений грунтового основания мачты составили 0,8 мм (рис. 6), горизонтальные перемещения - 0,14 мм, с учетом ползучести несущего слоя супеси мерзлой льдистой (Plaxis Soft-Soil-Creep Model), приращения вертикальных и горизонтальных перемещений составили 0,21 и 0,01 мм соответственно. Из чего можно заключить, что наблюдаемые деформации мачты (вертикальные перемещения 31 мм и горизонтальные перемещения 18,4 см) лишь на 3,2 \% объясняются грунтовыми условиями площадки.

\section{Выводы}

1. При проведении технического контроля мачты лазерным сканированием установлено, что объект имеет отклонения от вертикальной оси, которые равны: для вершины мачты 9,2 см, для вершины молниеотвода 9,5 см. Значение общего отклонения от вертикальной оси мачты с молниеотводом составило $18,4 \mathrm{~cm}$ в направлении юговосток, что превышает допустимый диапазон отклонения мачты - 8 см на высоте 80 м (СП 70.13330.2012. Несущие и ограждающие конструкции). Диаграммы отклонений мачты от вертикальной оси показали, что наклон мачты происходит не только в местах соединения секций, но и на всей длине каждой отдельной секции.

2. Анализ проведённой работы показал, что при выявлении отклонений у мачт с молниеотвода-

\section{СПИСОК ЛИТЕРАТУРЫ}

1. Светашков А.А., Куприянов Н.А., Манабаев К.К. Приближенный алгоритм решения задач линейной вязкоупругости // Вычислительная механика сплошных сред. - 2012. - Т. 5. № 3. - C. 292-299.

2. Перельмутер А.В., Сливкер В.И. Расчетные модели сооружений и возможность их анализа. - М.: ДМК Пресс, 2002. - 618 с.

3. Connor R.J., Hodgson I.C. Field Instrumentation, Testing, and Long-term Monitoring of High-mast Lighting Towers in the State of Iowa. - Ames, IA: Iowa Department of Transportation, 2006. $-56 \mathrm{p}$.

4. Field and Laboratory Studies on High-Mast Lighting Towers in Iowa / R.J. Connor, G. Callahan, M. Koob, I.C. Hodgson, B.L. Brakke // Proc. of the 2007 Mid-Continent Transportation Research Symposium. - Ames, Iowa, August 2007. - 16 p.

5. Dexter R.J. Investigation of Cracking of High-mast Lighting Towers. - Ames, IA: Iowa Department of Transportation, 2004. $46 \mathrm{p}$.

6. Design and commissioning of high mast lighting poles / S.I. Dilawer, A.R. Junaidi, S.N. Mehdi, G.M.S. Ahmed // IOSR Journal of Mechanical and Civil Engineering. - 2013. - V. 8. - Iss. 6. P. $40-46$.

7. Failure analysis of a high mast lamp post / G. Das, S. Chakrabarty, A.K. Dutta, S.K. Das, K.K. Gupta, R.N. Ghosh // Engineering Failure Analysis. - 2006. - V. 13 (17). - P. 1153-1158. ми высотой более 40 м главным условием, влияющим на корректность данных, являются конвективные потоки воздуха. С увеличением высоты мачты амплитуда колебания молниеотвода становится больше. Поэтому при техническом контроле за высотными объектами погодные условия съемки играют значительную роль в получении достоверных данных.

3. Моделирование напряженно-деформированного состояния грунтового основания позволило оценить вклад грунтовых условий в деформациях мачты. Предположение, что деформации мачты могут быть обусловлены специфическими характеристиками грунтового основания: высокой сжимаемостью грунтов сезонно-талого слоя, ползучестью многолетнемерзлых пород в длительной перспективе и изменениями механических свойств грунтов при изменении их температурного режима, не подтвердилось. Вертикальные перемещения грунтового массива составили всего 0,8 мм, горизонтальные перемещения - 0,14 мм. С учетом ползучести несущего слоя грунта приращения вертикальных и горизонтальных перемещений составили 0,21 и 0,01 мм соответственно. Таким образом, вклад грунтовых условий оказался минимальным. Фундамент устроен правильно, с учетом особенностей грунтов этой климатической зоны. Деформации мачты с молниеотводом на $96,8 \%$ обусловлены строительными свойствами надземной части конструкции, условиями ее монтажа и эксплуатации.

Исследование выполнено в Томском политехническом университете в рамках програмлы повышения конкурентоспособности Томского политехнического университета (средства ВИУ).

8. Sherman R.J., Hebdon M., Connor R. Fatigue Testing and Retrofit Details of High-Mast Lighting Towers / Engineering Journal (American Institute of Steel Construction). - 2016. - V. 53 (1). P. 61-72.

9. Goode J.S., Van de Lindt J.W. Reliability-based design of medium mast lighting structural supports // Structure and Infrastructure Engineering. - 2013. - V. 9. - № 6. - P. 594-600.

10. The potential of terrestrial laser scanners for digital ground surveys / D.D. Lichti, J. Franke, W. Cannel, K.D. Wheeler // J. Spat. Sci. - 2005. - V. 50. - № 1. - C. 75-89.

11. Рыльский И.А., Малеванная М.С. Наземные лазерные методы - новые подходы к информационному обеспечению географических исследований // Геодезия и картография. - 2014. № 8. - C. 38-48,

12. Селезнева Е.В. Применение лазерного сканирования в геоморфологических исследованиях // Вестник МГУ. Сер. 5. 2013. - № 2. - C. 47-53.

13. Assessing modern ground survey methods and airborne laser scanning for digital terrain modelling: a case study from the Lake District, England / M. Gallay, C.D. Lloyd, J. McKinley, L. Barry // Comput. and Geosci. - 2013. - V. 51. - P. 216-227.

14. Комиссаров А.В., Широкова Т.А., Комиссаров Д.В. Общий подход к изучению погрешностей наземной лазерной съемки, вызванных метрологическими свойствами объектов // Известия вузов. Геодезия и аэрофотосъемка. - 2013. - № 1. - С. 36-42. 
15. Terrestrial Laser Scanning Technology for Deformation Monitoring and Surface Modeling of Arch Structures / H. Yang, M. Omidalizarandi, X. Xu, I. Neumann // Composite Structures. 2017. - V. 169. - № 3. - P. 173-179.

16. Use of Terrestrial Laser Scanning Technology for Long Term High Precision Deformation Monitoring / R. Vezocnik, T. Ambrožič, 0. Sterle, G. Bilban, N. Pfeifer, B. Stopar // Sensors. 2009. - № 9. - P. 9873-9895.

17. Применение наземного лазерного сканирования и трехмерного информационного моделирования для неразрушающего контроля / А.Н. Яковлев, Е.В. Токмаков, О.В. Павлов, В.Г. Ли, А.Н. Искрин, Т.Г. Коржнева // Известия вузов. Физика. 2013. - T. 56. - № 12. - Ч. 2. - С. 72-75.

18. Lichti D.D. A method to test differences between additional parameter sets with a case // Photogrammetry and Remote Sensing. 2008. - V. 63 (2). - P. 169-180.

19. Yang H., Xu X., Neumann I. Laser scanning-based updating of a finite element model for structural health monitoring // IEEE Sensor. - 2016. - V. 7. - P. 2100-2104.

20. Terrestrial laser scanner for monitoring the deformations and the damages of buildings / G. Vacca, F. Mistretta, F. Stochino, A. Dessi // International Archives of the Photogrammetry, Remote Sensing \& Spatial Information Sciences. - 2016. - V. 41. Iss. B5. - P. 453-460.

21. Xu X., Yang H., Neumann I. Time-efficient filtering method for three-dimensional point clouds data of tunnel structures // Advances in Mechanical Engineering. - 2018. - V. 10. - № 5. P. 1-6.

22. СП 43.13330.2012 Акт. ред. СНиП 2.01.03-85. Сооружение промышленных предприятий. - М.: Минстрой России, 2012. $106 \mathrm{c}$.

23. СП 20.13330.2016 Акт. ред. СНиП 2.01.07-85*. Нагрузки и воздействия. - М.: Минстрой России, 2016. - 104 с.

24. СП 53-102-2004. Общие правила проектирования стальных конструкций. - М.: ЦНИИСК им. Кучеренко, 2004. - 131 с.

25. СП 16.13330.2010. Акт. ред. СНиП II-23-81\%. Стальные конструкции. Нормы проектирования. - М.: Минстрой России, 2011. $-178 \mathrm{c}$.

26. Latypov A., Zharkova N., Nuriyev I. Landslide hazard assessment in city under construction Innopolis (Russia) // IOP Conference Series: Earth and Environmental Science. - 2016. № $33 .-6 \mathrm{p}$.

27. Ганова С.Д. Геоэкологические аспекты создания и функционирования природно-технических систем в условиях криолитозоны Западной Сибири // Известия высших учебных заведений. Геология и разведка. - 2017. - № 5. - С. 58-64.
28. Комплексный метод снижения пылевой и газовой опасностей в угольных шахтах / О.В. Скопинцева, С.Д. Ганова, Н.В. Демин, В.И. Папичев // Горный журнал. - 2018. - № 11. - С. 97-100.

29. Ганова С.Д., Сотникова А.О. Нормализация риска в техносфере // Стратегия развития геологического исследования недр: настоящее и будущее (к 100-летию МГРИ-РГГРУ). Материалы Международной научно-практической конференции. - М.: МГРИ-РГГРУ, 2018. - Т. 2. - С. 108-109.

30. Епифанова Е.А., Строкова Л.А. Оценка деформаций исторического здания в Томске с помощью комплексного подхода, основанного на сочетании наземного лазерного сканирования и конечно-элементного моделирования // Известия Томского политехнического университета. Инжиниринг георесурсов. 2018. - T. 329. - № 5. - C. 27-41.

31. Строкова Л.А., Епифанова Е.А., Коржнева Т.Г. Численный анализ поведения основания опоры моста на старой железнодорожной линии // Известия Томского политехнического университета. Инжиниринг георесурсов. - 2017. - Т. 328. - № 5. C. $125-139$.

32. Строкова Л.А., Ермолаева А.В. Природные особенности строительства участка газопровода «Сила Сибири» на участке Чаяндинское нефтегазоконденсатное месторождение - Ленск // Известия Томского политехнического университета. - 2015. № 4. - T. 326. - C. 41-55.

33. Строкова Л.А., Ермолаева А.В. Районирование территории по степени опасности оседания земной поверхности при проектировании магистрального газопровода в южной Якутии // Известия Томского политехнического университета. Инжиниринг георесурсов. - 2016. - Т. 327. - № 10. - С. 59-68.

34. Strokova L. A. Modeling of tunneling-induced ground surface movement // IOP Conf. Series: Earth and Environmental Science. 2015. - V. 24. $-6 \mathrm{p}$.

35. Strokova L.A., Teterin E. A. Identification, diagnosis and ranking of risks of geohazard in pipeline and urbanized territories // IOP Conference Series: Earth and Environmental Science. 2016. - V. 43. $-6 \mathrm{p}$

36. Purgina D.V., Strokova L.A., Kuzevanov K.I. Modeling of changing hydrogeological conditions during construction of pier foundations on the Kama river bank // IOP Conference Series: Earth and Environmental Science. - 2016. - V. 33. - 6 p.

37. Численное моделирование влияния упрочнения грунтового массива цементно-песчаной инъекцией на деформации основания / Л.А. Строкова, С.С.Т. Тарек, В.В. Голубева, В. Иванов // Известия Томского политехнического университета. Инжиниринг георесурсов. - 2017. - Т. 328. - № 10. - С. 6-17.

Поступила 30.09.2018 2.

\section{Информация об авторах}

Enuфанова E.A., аспирант отделения геологии Инженерной школы природных ресурсов Национального исследовательского Томского политехнического университета.

Строкова Л.A., доктор геолого-минералогических наук, профессор отделения геологии Инженерной школы природных ресурсов Национального исследовательского Томского политехнического университета. 
УДК 624.131

\title{
NUMERICAL ANALYSIS OF DEFORMATIONS OF THE LIGHTING MAST BY GROUND LASER SCANNING AND FINITE ELEMENTS METHOD
}

\author{
Ekaterina A. Epifanova', \\ epifanovaea@tpu.ru \\ Lyudmila A. Strokova', \\ sla@tpu.ru \\ 'National Research Tomsk Polytechnic University,
30, Lenin Avenue, Tomsk, 634050, Russia.
}

The topic is relevant due to the necessity to improve approaches to estimation and prediction of deformations of the lighting mast. The solution of this problem is associated with many uncertainties, such as the lack of laboratory studies of the materials properties and field static and dynamic tests of such structures, the small number of analytical studies and monitoring data. The article presents the initial results of field studies of the high-mast lighting tower deformations and the numerical analysis of its stress-strain state.

This study aims to assess the stress-strain state of the foundation of the structure and compare the results of numerical simulation with the data on object deformation obtained during laser scanning.

Object of the research is the stress-strain state of the foundation of the lighting mast at the Vankor oil field.

Methods. The initial data for simulating the structure behaviour were obtained through archive data and field study. A reconnaissance survey of the site was completed. A program complex based on FEM is used to forecast the stress-strain state of the structure. Laser scanning technology allow accurate definition of deformations lying on every side of the structure and make an accurate three-dimensional model of the object. The terrestrial laser scanning objects held by 3D laser scanner Leica Scanstation C10; horizontal, vertical justification and binding study points to a local coordinate system using Total Station LEICA TS15 and GNSS receiver LEICA GS10; handling a cloud of points held in the software package Leica Cyclone 8.0; three-dimensional object modeling was carried out in the software package SolidWorks.

The results. The stress-strain state of the foundation of the lighting mast was studied in detail. A digital design model is created. The sections and general crack formation together with TLS measurement indicate that the structure is deformed. We estimated the minimum contribution of soil conditions to the deformation of the structure.

\section{Key words:}

Terrestrial laser scanning, modeling, deformation, mechanical behavior, stress-strain state, finite element model analysis.

The research was carried out at Tomsk Polytechnic University within the program of Enhancement of Tomsk Polytechnic University Competitiveness (VIU funds).

\section{REFERENCES}

1. Svetashkov A. A., Kupriyanov N. A., Manabayev K. K.. Approximate algorithm for solving problems of linear viscoelasticity. Computational mechanics of continuous media, 2012, vol. 5, no. 3, pp. 292-299.

2. Perelmuter A.V., Slivker V.I. Raschetnye modeli sooruzheniy vozmozhnost ikh analiza [Calculation Models of Structures and Possibilities of their Analysis]. Moscow, DMK Press Publ., 2002. $618 \mathrm{p}$.

3. Connor R.J., Hodgson I.C. Field Instrumentation, Testing, and Long-term Monitoring of Highmast Lighting Towers in the State of Iowa. Ames, IA, Iowa Department of Transportation, 2006. $56 \mathrm{p}$.

4. Connor R.J., Callahan G., Koob M., Hodgson I.C., Brakke B.L. Field and Laboratory Studies on High-Mast Lighting Towers in Iowa. Proc. of the 2007 Mid-Continent Transportation Research Symposium. Ames, Iowa, August 2007. 16 p.

5. Dexter R.J. Investigation of Cracking of High-mast Lighting Towers. Ames, IA, Iowa Department of Transportation, 2004. $46 \mathrm{p}$.

6. Dilawer S.I., Junaidi A.R., Mehdi S.N., Ahmed G.M.S. Design and commissioning of high mast lighting poles. IOSR Journal of Mechanical and Civil Engineering, 2013, vol. 8, no. 6, pp. 40-46.

7. Das G., Chakrabarty S., Dutta A.K., Das S.K., Gupta K.K., Ghosh R.N. Failure analysis of a high mast lamp post. Engineering Failure Analysis, 2006, vol. 13 (17), pp. 1153-1158.
8. Sherman R.J., Hebdon M., Connor R. Fatigue Testing and Retrofit Details of High-Mast Lighting Towers. Engineering Journal (American Institute of Steel Construction), 2016, vol. 53 (1), pp. 61-72.

9. Goode J.S., Van de Lindt J.W. Reliability-based design of medium mast lighting structural supports. J. Structure and Infrastructure Engineering, 2007, vol. 9, no. 6, pp. 594-600.

10. Lichti D.D., Franke J., Cannel W., Wheeler K.D. The potential of terrestrial laser scanners for digital ground surveys. J. Spat. Sci., 2005, vol. 50, no. 1, pp. 75-89.

11. Rylsky I.A., Malevannaya M.S. Terrestrial laser methods - new approaches to information support of geographical research. Geodeziya i kartografiya, 2014, vol. 8, pp. 38-48. In Rus.

12. Selezneva E.V. Application of laser scanning in geomorphologic studies. MSU Vestnik. Series 5, 2013, vol. 2, pp. 47-53. In Rus.

13. Gallay M., Lloyd C.D., McKinley J., Barry L. Assessing modern ground survey methods and airborne laser scanning for digital terrain modelling: a case study from the Lake District, England. J. Comput. and Geosci., 2013, vol. 51, pp. 216-227.

14. Komissarov A.V., Shirokova T.A., Komissarov D.V. General approach to the study of errors of terrestrial laser shooting caused by metrological properties of objects. Izvestiya vuzov. Geodeziya $i$ aerofotosemka, 2013, no. 1, pp. 36-42. In Rus.

15. Yang H., Omidalizarandi M., Xu. X., Neumann I. Terrestrial Laser Scanning Technology for Deformation Monitoring and Surface Modeling of Arch Structures. Composite Structures, 2017, vol. 169 , no. 3, pp. 173-179. 
16. Vezočnik R., Ambrožič T., Sterle 0., Bilban G., Pfeifer N., Stopar B. Use of Terrestrial Laser Scanning Technology for Long Term High Precision Deformation Monitoring. Sensors, 2009, no. 9, pp. 9873-9895.

17. Yakovlev A.N., Tokmakov E.V., Pavlov 0., Li V.G., Iskrin A.N., Korzhneva T.G. Application of terrestrial laser scanning and three-dimensional information modeling for non-destructive testing. Izvestiya vuzov. Fizika, 2013, vol. 56, no. 12 (2), pp. 72-75. In Rus.

18. Lichti D.D. A method to test differences between additional parameter sets with a case study in terrestrial laser scanner self-calibration stability analysis. ISPRS Journal of Photogrammetry and Remote Sensing, 2008, vol. 63, no. 2, 169-180.

19. Yang H., Xu X., Neumann I. Laser scanning-based updating of a finite element model for structural health monitoring. IEEE Sensor, 2016, no. 7, pp. 2100-2104

20. Vacca G., Mistretta F., Stochino, F., Dessi A. Terrestrial laser scanner for monitoring the deformations and the damages of buildings. International Archives of the Photogrammetry, Remote Sensing \& Spatial Information Sciences, 2016, vol. 41, Iss. B5, pp. 453-460.

21. Xu X., Yang H., Neumann I. Time-efficient filtering method for three-dimensional point clouds data of tunnel structures. Advances in Mechanical Engineering, 2018, vol. 10, no. 5, pp. 1-6.

22. SP 43.13330.2012 Act. ed. SNiP 2.01.03-85 Sooruzhenie promyshlennykh predpriyatiy [Construction of industrial enterprises]. Moscow, The Ministry of Construction of Russia, 2012. $106 \mathrm{p}$.

23. SP 20.13330.2016 Nagruzki i vozdeystviya [Loads and impacts] Moscow, The Ministry of Construction of Russia, 2016. $104 \mathrm{p}$.

24. SP 53-102-2004. Obshchie pravila proektirovaniya stalnykh kon struktsy [General rules for design of steel structures]. Moscow, The Ministry of Construction of Russia, 2004.131 p.

25. SP 16.13330.2010 Stalnye konstruktsii. Normy proektirovaniya [Steel structures. Design standards]. Moscow, The Ministry of Construction of Russia, 2011. 178 p.

26. Latypov A., Zharkova N., Nuriyev I. Landslide hazard assessment in city under construction Innopolis (Russia). IOP Conference Series: Earth and Environmental Science, 2016, vol. 33, $6 \mathrm{p}$.

27. Ganova S.D. Geoecological aspects of creation and functioning of natural and technical systems in the conditions of the cryolithozone of Western Siberia. Proceedings of Higher Schools. Geology and exploration, 2017, no. 5, pp. 58-64. In Rus.

28. Scopintseva O.S., Ganova S.D., Demin N.V., Papichev V.I. Integrated method of dust and gas hazard reduction in coal mines.
Gorny zhurnal, 2018, no. 11, pp. 97-100. DOI: 10.17580/gzh.2018.11.18.

29. Ganova S.D., Sotnikova A.0. Normalizatsiya riska v tekhnosfere [Risk normalization in technosphere]. Strategiya razvitiya issledovaniya nedr: nastoyashchee $i$ budushchee ( $k$ 100-letiyu MGRI-RGGRU). Materialy Mezhdunarodnoy nauchno-prakticheskoy konferentsii [Strategy of development of geological studies of mineral resources: present and future (the $100^{\text {th }}$ anniversary of MGRI-RSGPU). Materials of International scientific-practical conference]. Moscow, 2018. Vol. 7, pp. 93-95.

30. Epifanova E.A., Strokova L.A. Evaluation of deformation of a historic building in Tomsk by an integrated approach based on Terrestrial Laser Scanner and Finite Element Modeling. Bulletin of the Tomsk Polytechnic University, Geo Assets Engineering, 2018. vol. 329, no. 5, pp. 27-41. In Rus.

31. Strokova L.A., Epifanova E.A., Korzhneva T.G. Numerical analysis of bridge foundation behaviour on the old railway line. Bulletin of the Tomsk Polytechnic University. Geo Assets Engineering, 2017, vol. 328, no. 5, pp. 125-139. In Rus.

32. Strokova L.A., Ermolaeva A.V. Natural features of construction of the main gas pipeline «The Power of Siberia» on a site Chayandinskoye oil and gas field - Lensk. Bulletin of the Tomsk Polytechnic University, 2015, vol. 326, no. 4, pp. 41-55.

33. Strokova L.A., Ermolaeva A.V. Zoning according to the hazard level of earth surface subsidence when designing the main gas pipeline in south Yakutia. Bulletin of the Tomsk Polytechnic University. Geo Assets Engineering, 2016, vol. 327, no. 10, pp. 59-68.

34. Strokova L.A. Modeling of tunneling-induced ground surface movement. IOP Conf. Series: Earth and Environmental Science, 2015, vol. 24, 012030, 6 p.

35. Strokova L.A., Teterin E.A. Identification, diagnosis and ranking of risks of geohazard in pipeline and urbanized territories. IOP Conference Series: Earth and Environmental Science, 2016, vol. 43, 012051, $6 \mathrm{p}$.

36. Purgina D.V., Strokova L.A., Kuzevanov K.I. Modeling of changing hydrogeological conditions during construction of pier foundations on the Kama river bank. IOP Conference Series: Earth and Environmental Science, 2016, vol. 33, 01246, 6 p.

37. Strokova L.A., Tarek S.S.T., Golubeva V.V., Ivanov V. Numerical modeling of influence of soil mass reinforcement with cementsand grouting on foundation deformation. Bulletin of the Tomsk Polytechnic University. Geo Assets Engineering, 2017, vol. 328, no. 10 , pp. 6-17.

Received: 30 September 2018.

\section{Information about the authors}

Ekaterina A. Epifanova, postgraduate student, National Research Tomsk Polytechnic University.

Lyudmila A. Strokova, Dr. Sc., professor, National Research Tomsk Polytechnic University. 